Published in Experimental Economics 19(3), 663-685, 2016.

\title{
Social preferences and lying aversion in children
}

\author{
By Valeria Maggian And Marie Claire VilleVaL*
}

\begin{abstract}
While previous research has shown that social preferences develop in childhood, we study whether this development is accompanied by reduced use of deception when lies would harm others, and increased use of deception to benefit others. In a sample of children aged between 7 and 14, we find strong aversion to lying at all ages. Lying is driven mainly by selfish motives and envy. Children with stronger social preferences are less prone to deception, even when lying would benefit others at no monetary cost. Older children lie less than younger children and use self-justification to lie.
\end{abstract}

Keywords: Lying aversion, deception, social preferences, children, experiment.

JEL-codes: C91, D03, D63

\footnotetext{
* Valeria Maggian: University of Milano-Bicocca, Department of Economics, Piazza dell'Ateneo Nuovo, 1, 20126, Milano, Italy (valeria.maggian@unimib.it).

Marie Claire Villeval: Université de Lyon, F-69007, France; CNRS, GATE Lyon St Etienne, 93, Chemin des Mouilles, F-69130, Ecully, France; IZA, Bonn, Germany (villeval@gate.cnrs.fr).
}

Acknowledge: This research has been supported by a grant from the French National Research Agency (ANR, EMCO program, HEIDI grant) and was performed within the framework of the LABEX CORTEX (ANR-11-LABX-0042) of Université de Lyon, within the program "Investissements d'Avenir" (ANR-11IDEX-007) operated by the French National Research Agency (ANR). We thank participants at the ESA world meeting in New-York, the EASP conference in Amsterdam, the Toulouse-Lyon BEE workshop in Lyon, the Florence Workshop on Behavioral and Experimental Economics, the workshop on Understanding employees' dishonesty behavior in the workplace in Dijon, and seminar participants at the University of Paris I for useful comments. 


\section{INTRODUCTION}

Recent research has shown that some people seem to have a preference for honesty based on an internalized moral norm. Contrary to the notion that individuals rationally violate moral norms provided this brings marginal net benefits, people may refrain from lying in such a situation. However, pursuing a moral conduct may sometimes conflict with the desire to improve others' welfare. When the pursuit of other-regarding preferences implies lying, individuals face a moral dilemma. Conditioning lying behavior on preferences over distribution is therefore fundamental. Analyzing such a dilemma is extremely relevant in childhood, a crucial phase in the process of development of both other-regarding preferences and moral reasoning. Indeed, psychologists have shown that persistent lying at a young age may be associated to a number of disruptive behaviors (Gervais et al. 2000; for a review, see Stouthamer-Loeber 1986).

In this paper we analyze whether children's deceitful behavior depends on their otherregarding preferences in presence of economic incentives. Collecting data both on deceptive behavior and on social preferences in a natural environment is, however, extremely difficult. Using survey data with children on this topic is unlikely to provide reliable information. For that reason, we conducted a controlled experiment in classrooms in Italy. Our experiment involved 637 children in three age groups, from middle childhood (7-8 and 9-10 years old) to early adolescence (11 and 14 years old). We gave children the opportunity to lie in order to achieve their preferred outcome, making them conscious that their choice would influence both their own payoff and their partner's welfare. We study whether having a preference for an other-regarding or for a self-regarding allocation of resources affects children's willingness to lie to achieve it, according to their age and gender. 
Precisely, our experiment consists of a modified version of the dictator game that was played in two stages. The first stage allows us to measure the social preferences of children, while the second stage aims at characterizing the lying propensity. In the first stage each child had to choose between two options for the allocation of resources between himself and an anonymous partner. In the second stage a random device selected one of the two same options. Each child was then asked to report the option that had been randomly drawn. If this option did not correspond to his preferred one, the child had the possibility to lie by reporting his preferred option instead of the observed one. Both decisions were made in private in a separate room. This design allows us to examine whether children's individual lying behavior is conditional on their preferences over allocations. We implemented three different treatments with different allocation options to study various social preferences (namely, altruism, inequity aversion, and efficiency concerns). Importantly, equal payment does not always represent the fair choice so as to avoid obvious focal points across treatments.

Our main contribution is the study of the co-evolution of social preferences and lying behavior, using a combination of simple social preferences and dishonesty measures. The design of the experiment and the use of a computerized recording method allow us to identify honesty at the individual level. It also permits to analyze how often children activate the random device to increase their chance to observe their favorite outcome. This may capture the search for self-justification in the reporting decision, as psychologists have shown the importance of maintaining a positive self-image while lying (Mazar et al. 2008, Shalvi et al. 2011, Pittarello et al. 2015).

We hypothesized two main plausible developmental pathways. On the one hand, since unconditional lying aversion has been observed in adults, we expected the internalization of 
the value of honesty to develop in childhood. On the other hand, since adults are sensitive to the consequences of their lies on others we expected that older children, who are more likely to care about other's welfare as they age, become also more likely to lie to benefit others.

Our results show that a large fraction of children is reluctant to tell lies. They also show that lying behavior does not increase linearly across age groups, as we observe that 9-10 years old children are more likely to lie than the oldest ones. Indeed, while otherregarding preferences develop with age, lying behavior does not develop along the same path.

Our analysis at the individual level reveals that ethical preferences are correlated with social preferences. The frequency of lie telling is much higher for children having a preference for an allocation of resources that reveals selfishness or envy, independently on age, than for socially oriented children. For example, when the choice in the first stage of the experiment was between a selfish and an equal allocation of resources, children who exhibited inequity aversion were less likely to lie in the second stage to implement an equal sharing compared to children who made an initial selfish choice. For their part, altruistic children never lied. Finally, when the choice was between an efficient and an equal allocation of resources, children who exhibited efficiency concerns were less prone to lie to increase the recipients' payoff than envious children who lied to decrease the other's payoff without increasing their own payoff. Since we find more social preferences in older children, this explains that, on average, the frequency of lies is lower among older children. Moreover, male children tell more lies that hurt others compared to female children, but the gender gap tends to disappear when aging. 
Interestingly, we find that older children, compared to younger ones, are more likely to lie if they can manipulate the truth at their advantage without altering their self-image, by activating the random device several times until they can observe their preferred outcome. This suggests that older children need more self-justification to deceive.

The remainder of our study proceeds as follows. Section 2 briefly reviews the recent literature. Section 3 describes our experimental design. Section 4 develops the experimental results and Section 5 discusses these results and concludes.

\section{LITERATURE REVIEW}

Extensive research has established that individuals make conscious decisions implying giving up personal gains to help others, thus revealing other-regarding preferences towards strangers (Heinrich et al. 2001, Fehr and Fischbacher 2003, Dawes et al. 2007, Tricomi et al. 2010). In contrast with the standard economics-of-crime approach, it has been shown that adults may refrain from acting dishonestly even when this would increase their monetary payoffs (Gneezy 2005; Charness and Dufwenberg 2006, Lundquist et al. 2009, Lopez-Perez and Spiegelman 2013; Pruckner and Sausgruber 2013, Gibson et al. 2013; see Irlenbusch and Villeval 2015 for a survey of recent evidence). There is a large heterogeneity in the attitudes towards lying, with a continuum of preferences for truthfulness (Gibson et al. 2013). In particular, (dis)honesty may be conditional on social preferences. Indeed, it has been shown that the decision to lie is sensitive to the consequences of the lie on others' well-being (Gneezy 2005, Hurkens and Kartik 2009): while people are less prone to act dishonestly when a lie hurts others, a substantial fraction of individuals is willing to tell "white lies", i.e. lies that help another person possibly at a personal cost (Erat and Gneezy 2012). Evidence of unconditional honesty has also been 
found by Abeler et al. (2014) and Erat and Gneezy (2012). . Erat and Gneezy (2012), in their sender-receiver experiment, found that a fraction of senders were reluctant to send an untruthful message to their partners, even if both subjects would have benefited from it. Note that Vanberg (2015) questions the reliability of Erat and Gneezy's (2012) experimental design in drawing such a conclusion. Based on a slightly different protocol in which it is made clear that both players' interests are aligned and where lying would lead to a Pareto improvement, he rejects pure lying aversion and suggests instead that subjects' moral attitudes are rarely independent of consequences. We find evidence of lying aversion in our experiment, as children holding other-regarding preferences are reluctant to tell white lies. However in contrast to Erat and Gneezy (2012) and Vanberg (2015) papers, in our experiment white lies are never associated with both subjects equally benefiting from them.

Dimensions others than social preferences may also condition dishonesty. Mazar et al. (2008) and Fischbacher and Föllmi-Heusi (2013) show that people do not fully exploit their lying opportunities because they care about maintaining a positive self-concept of their morality. To preserve a positive self-image, adults need (self) justification to lie (Shalvi et al. 2011, Pittarello et al. 2015). Finally, attitudes towards lying seem to be also conditional on individual characteristics. Dreber and Johannesson (2008) find that females tell less "black lies", i.e. lies that harm others, than males, a difference that, however, disappears with larger stakes (Childs, 2012).

We contribute to this literature by providing the first study on whether children's lying behavior is affected by the evolution of social preferences and individual characteristics as age and gender. 
The analysis of children's behavior helps understanding how individuals form their social preferences and internalize moral norms ${ }^{1}$. It has been found that individuals become less selfish as they age (Harbaugh et al. 2003), although this evidence may depend on children's socio-economic status (Benenson et al. 2007). Egalitarianism develops with age (Fehr et al. 2008), with 7-8 years old children showing inequality aversion, whereas children at age 3-4 are more likely to take self-interested decisions. However, when aged 8 to 17 years, egalitarianism becomes less frequent and altruism much more prominent (Fehr et al. 2013). Efficiency concerns also develop with age since social welfare preferences are more likely to motivate the choices of older subjects (Martinsson et al. 2011). Moreover, women are more frequently classified as egalitarian than men: between the age of 10 to 15 years old, girls prefer to reduce payoff difference for envy motives whereas boys are more driven by social welfare improvement.

The major innovative feature of our study lies in the possibility to investigate both the development of children other-regarding preferences with respect to age and gender and its interaction with dishonest behavior.

The development of cheating behavior, a major milestone in the analysis of children's moral reasoning, has been a focus of investigation in psychology ${ }^{2}$ (see Shepherd et al. 1971, Stouthamer-Loeber 1986, Bussey 1999, Talwar and Crossman 2011). Children's understanding of the opportunity to not tell the truth in order to pursue personal interest or to avoid punishment emerges as early as three years of age (Lewis et al. 1989, Chandler et

\footnotetext{
${ }^{1}$ Experiments with children are becoming more frequent in economics. While initial analysis was focused on the development of social preferences (Harbaugh and Krause 2000, Fehr et al. 2008, Almås et al. 2010, Martinsson et al. 2011, Fehr et al. 2013) and trust (Harbaugh et al. 2003, Sutter and Kocher 2007), recent research also investigates willpower (Bucciol et al. 2010, Bucciol and Piovesan 2011), competitiveness (Gneezy and Rustichini 2004, Sutter and Rützler 2010, Dreber et al. 2011, Andersen et al. 2013), risk and ambiguity attitudes (Harbaugh et al. 2002, Sutter et al. 2013).

${ }^{2}$ Piaget (1965) is among the first psychologists suggesting a theory of moral development.
} 
al. 1989). Deceitful behavior evolves during school years as children develop executive control functions and theory of mind (Talwar et al. 2007, Talwar and Lee 2008), and the ability to infer correctly which social and moral norms may be violated when lying (Broomfield et al. 2002, Xu et al. 2010, Bussey 1992). These studies suggest a decreasing trend of cheating behaviors from late childhood, 8-10 years old, to early adolescence, 11-14 years old. However, most studies disregard how the decision is affected by its economic consequences on others' welfare, which is central in our study.

Only two studies in economics have investigated children lying behavior. When individual behavior is not observable and the lie does not affect others' payoff but just increases the liar's outcome, Bucciol and Piovesan (2011) find that most children cheat uniformly between the age of 5 and 15. In a recent study on children aged 10/11 and 15/16 years, Glätzle-Rützler and Lergetporer (2014) show that the propensity to lie decreases with age; this effect is driven by the fact that younger children tell more weak Pareto white lies than teenagers, i.e. lies that increase one's payoff with no impact on others. A major difference with respect to this study is that we elicit separately social preferences and lying behavior of each individual by means of a simple game. This allows us to measure the extent to which our results reflect an aversion to lying as opposed to preferences over allocation of payoffs. Besides using different age categories, we also use a between-subject design to avoid carryover effects (i.e. moral cleansing). 


\section{EXPERIMENTAL METHODS}

To study how children's other-regarding preferences correlate with ethical preferences over time, we designed a two-stage computerized experiment based on a simplified Dictator game, using z-Tree (Fischbacher 2007). ${ }^{3}$

\subsection{Participants and procedures}

We ran the experiment in 34 classes of three schools in Vicenza and Treviso (Italy), with an average of 19 students per class (S.D.=3.45). In total 637 children aged between 7 and 14 years took part in this experiment (326 females and 311 males). We chose a range of ages that has been shown to be important with respect to both the development of social preferences (Fehr et al. 2013) and the development of moral values (indeed, in psychology, Talwar and Crossman (2011) have suggested that lying behavior may peak in the elementary school while decreasing thereafter).

The same session logistics was used in all schools. After having planned the experimental sessions with headmasters and teachers we asked the latter to give children's parents the informative material, the consent form and a questionnaire asking demographic information about children. Teachers and headmasters were aware that they were not allowed to reveal the purpose of the experiment to children and parents, or to provide details about the content of the protocol. For security reasons, the teachers were present in the classroom during the experiment (but the children were alone in the decision room); they agreed not to communicate with the children about the experiment during the session.

\footnotetext{
${ }^{3}$ We think that asking children to use a computer was not an issue. Indeed, according to recent research, an Italian child from age 2 to 11 spends on average 22 hours per month on the computer and children from Kindergarten 2 and Grade 1 (mean age: 6 and 7) are generally able to use a mouse to operate educational softwares (Donker and Reitsma, 2007). Moreover, the experimenter stood nearby the decision room in case the child needed help. No child has encountered any problem with the computer.
} 
We acknowledge that the experimental environment may play a role since school also participates in teaching moral norms, as we discuss in the conclusion section. However, the school mimics an environment natural for the children and is almost similar to all subjects. Many previous experiments with children were run in schools (Fehr et al. 2008, Benenson et al. 2007, Martisson et al. 2011, Fehr et al. 2013, Sutter et al. 2013, Bauer et al. 2014), in presence of the teacher, of the experimenter, or both (Harbaugh et al. 2003, Fehr et al. 2008, 2013). As in Sutter et al. 2013, our experiment was conducted during regular school hours. The main advantage of running the experiment in schools during the class is the limitation of a potential selection bias since school attendance is mandatory. ${ }^{4}$

Parents had the opportunity to contact us for getting clarifications. Only children whose parents had signed the consent form could participate in the experiment. We used a room that was separated from the classroom to allow each child to make his decisions alone, in private, while the experimenter was waiting outside (see on-line Appendix 2). At the beginning of the sessions, each child was randomly paired with an anonymous classmate. None of the children was informed about the identity of his partner and this was made common knowledge. ${ }^{5}$ Instructions were explained to all children in the class but questions were asked and answered privately. Instructions for the two stages of the

\footnotetext{
${ }^{4}$ Note that very few children in these towns go to private schools or are home schooled. Thus, we avoid problems of large self-selection and drop-outs in the sample that could arise if running the experiment after class, in holiday centers, or within the family. For ethical reasons, we had to ask both for parents' consent and children's willingness to participate in the experiment. We contacted 742 parents, and 686 gave their consent (92 percent). The size of the final dataset is reduced to 637 because 2 children voluntary decided not to participate and 42 children were missing the day of the experiment. This acceptance rate is the same as in Fehr et al. (2008). Thus, the self-selection bias should be very limited.

${ }^{5}$ The full set of instructions is available in the on-line Appendix 1. Anonymity of choices was ensured both between participants and with respect to teachers, headmasters and children's family. In addition to the fact that decisions were made in isolation, children were made aware that there was no possibility to learn about others' choices. During the experiment we always refer to children by using the number that was randomly assigned to each of them at the beginning of the session. Implementing a double blind procedure was impossible since we wanted to collect also demographic characteristics. We had no question from any child on whether his decisions could be observed or not.
} 
experiment were read in a row: in such a way, children had to go to the other room only once to play the game, reducing the possibility of communicating their choices to their peers. This procedure saved time (the average duration of the game was about 50 minutes). It also required that children's attention remains focused for the entire duration of the instructions. To facilitate understanding, we kept the instructions as simple as possible and a summary of the instructions was briefly reminded and explained to each child individually before he entered the decision room. We asked each child whether everything was clear and we answered questions but we did not use control questions. ${ }^{6}$

Each child was randomly paid only according to the choice he has made in the first or in the second stage. Children were told which stage was paid only at the end of the experiment. Moreover, they were explained that only the choice made by one of the two members in the pair in the selected stage would be randomly selected for payment. ${ }^{7}$ In the payment phase, the earned tokens were exchanged with prizes (pencils, stickers, and small bracelets): the higher the number of tokens earned by the child, the more prizes he would receive. ${ }^{8}$ These prizes were shown to the children from the beginning of the session. Each

\footnotetext{
${ }^{6}$ We mentioned several times in the instructions that children were allowed to ask questions both when we read the instructions in public and when we summarized them in front of each of them, individually. We cannot totally exclude confusion but there is no reason to think that it would lead to specific preferences or to certain type of lying behavior, as errors should go in both directions. The great majority of the children did not experience any problem in managing the whole process: Only four children, once entered the room, went back again before starting the task and asked clarification questions. Moreover, we ran the experiment in March and April, so that 7 years old children have already experienced almost 7 months of school and have already developed the basic abilities in mathematics, logic and Italian to be able to successfully understand and complete the whole task.

7 In the case there was an odd number of children in the class, one child was randomly selected to play the game without a partner (this was not made common information and none of the children asked about it): one of his two decisions was randomly selected for determining the child's payment.

${ }^{8} \mathrm{~A}$ picture of the prizes can be found in the on-line Appendix 3. We were not allowed to use monetary prizes but the children were really enthusiastic at the prospect of earning these prizes. With 3 points children could choose between having 1 colored pen, 1 colored double pencil, 5 shokky-bandz or 1 packet of stickers; 5 points could be exchanged for 2 colored pens or 2 double colored pencils or 10 shokky bandz or 2 packets of stickers; 7 points gave the opportunity to choose between 3 colored pens, 3 double colored pencils, 1 packet of shokky bandz (in each packet there are 14 shokky bandz) or 3 packets of stickers. It was also possible to
} 
type of prize was available in large quantity so that children could not be afraid of a shortage of their preferred items. Moreover, since Blake and Rand (2010) found that 3- to 6-year old children playing a Dictator game are more likely to donate their least favorite stickers than their favorite ones, we avoid any effect played by the value of the currency used by assuring a variety of prizes.

\subsection{Timing of decisions}

The experiment consists of two stages and this was made common information. In the first stage, each child was asked to decide how to allocate a certain amount of tokens between himself and an anonymous classmate. Two options were available: one option gave both children the same number of tokens; the alternative, depending on the treatment, assigned the child more or less tokens than his partner. The child's choice indicated his social orientation, as detailed below.

In the second stage, in order to elicit attitudes towards lying, we asked each child to press a button on the computer located in the separate room to make a shape - a sun or a star - appear on the screen (see Figure 1). The child was informed that each shape would appear with one chance out of two. Each shape was associated with one of the two allocation options used in the first stage. It was made clear that the shape appearing was random and independent of their decision in the first stage. The child was instructed to report the shape observed on the screen on a reporting sheet (see Figure 1). ${ }^{9}$ Since the corresponding allocation option reported by the child was implemented if the second stage

mix the prizes. We implemented a higher exchange rate for payments in the 14 years old group to ensure that the marginal incentives were comparable across ages.

${ }^{9} \mathrm{We}$ used this indirect procedure instead of displaying the two allocation options because we thought that it was more neutral. Furthermore, it does not seem to have created any confusion in the children's mind: they understood the correspondence between the shapes and the allocation options. 
was selected for payment, each child had thus the opportunity to misreport the observed shape to get his preferred allocation option. This was, of course, not made explicit.

\section{[Insert Figure 1 about here]}

Similarly, we did not mention in the instructions that it was possible to click several times to make the shape corresponding to the favorite allocation option appear. We let the children explore and use or not this opportunity. ${ }^{10}$ The computer program recorded for each child the shape that actually appeared on the screen and the number of times the child pressed the button making a shape appear on the screen. The option to click several times aims at investigating whether children develop strategies to maintain a positive self-image about being honest while acting dishonestly. In a previous experiment, Lundquist et al. (2009) showed that the distance between a lie and the truth increases the difficulty to tell a lie. This has also been observed by Pittarello et al. (2015). Our design allows us to test for this possibility: do children lie more when they can make their favorite shape appear after refreshing their screen once or more?

\subsection{Treatments}

We vary the treatments to investigate how various social preferences affect lying behavior. When organizing the experiment, we randomly pre-assigned each class to one of three treatments (Selfishness, Efficiency, or Altruism treatment). One allocation option is common to all three treatments: this option enables an egalitarian distribution of 5 tokens to both the decision-maker and his partner. The equal share was chosen as the benchmark since egalitarianism has been shown to be a major driver of human actions (Dawes et al.

\footnotetext{
${ }^{10}$ Alternatively, we could have made the multi-clicking option common knowledge among children while asking them to report the first shape that appeared on their screen (similarly to Fischbacher and Föllmi-Heusi 2013 in their die experiment, for example). We proceeded differently to avoid possible confusion in children. We actually provide evidence that all children were equally able to use multi-clicking, meaning that its accessibility was not limited by age.
} 
2007). The alternative option creates advantageous or disadvantageous inequality, depending on the treatment.

In the Selfishness treatment, by choosing the $(7,3)$ alternative option, the child increases his own payoff by decreasing that of his partner, revealing selfishness. Choosing $(5,5)$ instead of $(7,3)$ reveals inequality aversion. In the Altruism treatment, instead of choosing $(5,5)$ the child can increase his partner's payoff by choosing the alternative $(3,7)$ option. Since this choice reduces the child's own payoff, it provides evidence of altruism. Finally, in the Efficiency treatment, the child can increase his partner's payoff at no cost to himself by choosing $(5,7)$ instead of the $(5,5)$ option. Efficiency concerns are identified when the percentage of children choosing the $(5,7)$ option is significantly above 50 percent. On the contrary, if more than 50 percent choose the $(5,5)$ option, this may be driven by envy or inequality aversion.

The advantage of our design is that it allows us to measure both deception at the individual level (i.e. reporting a different shape with respect to the first appeared) and its relationship with social preferences, according to the children's age and gender. ${ }^{11}$

\section{RESULTS}

We first examine the children's social preferences by age and by gender, before relating them to children's deceptive behavior.

\footnotetext{
${ }^{11}$ We did not elicit each child's perception of black and white lies. However, in a psychological study on categorization and evaluation of various types of lies Bussey (1999) found that 8- and 11-year-old children classified nearly all false statements as lies and true statements as truths, regardless of context. When they had to evaluate lies, children from all age groups evaluated more negatively antisocial lies than white lies. This suggests that there is a consensus among children of these different age groups about how to identify and categorize lies.
} 


\subsection{Children's social preferences}

Figure 2 shows the percentage of children choosing the equal sharing $(5,5)$ in the first stage of the experiment, by age and by treatment. We find that as children age, selfishness becomes less prominent and efficiency concerns develop.

In the Selfishness treatment, 48 percent of the 7-8 year olds, 50 percent of the 9-10 year olds and 63.22 percent of the 11 and 14 year olds choose the egalitarian instead of the selfish option. $\chi^{2}$-tests indicate that children in the oldest age category are significantly more likely to choose the $(5,5)$ instead of the $(7,3)$ option in comparison with both the $7-8$ and the 9-10 years old children ( $p=0.079, \mathrm{~N}=173$, and $p=0.052$ and $\mathrm{N}=162$, respectively). The time path of egalitarian choices is reversed when we consider the Efficiency treatment. A $\chi^{2}$-test confirms at a 5 percent significance level that the 11 and 14 year olds are more likely to prefer the $(5,7)$ option than the egalitarian one compared to the $7-8$ year olds ( $p=0.035$ ), with no difference with the 9-10 year olds $(p=0.464)$. Indeed, while only 20.27 percent of younger children choose the efficient option, this percentage increases to 30.28 percent for the 9-10 year olds and to 35.11 percent for the 11 and 14 year olds. We interpret this result as an evidence of children becoming more concerned with efficiency as becoming older, since a binomial test strongly rejects the hypothesis that the rate of egalitarian choices corresponds to a random choice in all age groups $(p<0.01)$. In contrast, in the Altruism treatment 96.40 percent of the children prefer equal sharing to the disadvantageous inequality alternative, with no age differences.

\section{[Insert Figure 2 about here]}

Next, we consider the impact of gender on the development of social preferences. In the Selfishness treatment, 64.06 percent of females but only 43.33 percent of males choose 
to share tokens equally ( $p=0.001, \chi^{2}$-test, $\mathrm{N}=248$ ). Similarly, in the Efficiency treatment, 77.04 percent of females but only 64.79 percent of males choose $(5,5)\left(p=0.025, \chi^{2}\right.$-test, $\mathrm{N}=277$ ). In the Altruism treatment, 100 percent of females and 91.84 percent of males prefer the egalitarian to the altruistic option ( $p=0.035$, Fisher's exact tests two-tailed, $\mathrm{N}=111$ ). This shows that females are more averse than males to both advantageous and disadvantageous inequality.

However, some of these gender differences reduce as children age. In the Selfishness treatment, 7-8 year old females more frequently choose the egalitarian option than males (59.46 percent of females and 36.84 percent of males). This gender gap increases at age 9$10\left(p=0.005, \chi^{2}\right.$-test, $\left.\mathrm{N}=86\right)$ but diminishes strongly at ages 11 and 14 (see Figure $3 \mathrm{~A}$ ). Indeed, the percentage of egalitarian choices increases from 33.33 percent at age 9-10 to 58.14 percent at ages 11 and 14 for boys, while for girls it remains almost stable at, respectively, 63.83 and 68.18 percent. In the Efficiency treatment, the gender gap remains approximately constant across ages (Figure 3B) with efficiency concerns increasing for both genders. $^{12}$

\section{[Insert Figures $3 A$ and $3 B$ about here]}

Our first set of results replicates most of the previous literature (Fehr et al. 2008, Blake and Rand 2010, Martinsson et al. 2011, Fehr et al. 2013), except that we find the opposite result than Almås et al. (2010) who observed a stronger concern for efficiency in male compared to female adolescents. Our results can be summed up as follows: ${ }^{13}$

Result 1: From 7 to 14 years old children, selfishness diminishes and efficiency concerns increase.

\footnotetext{
${ }^{12}$ In the Efficiency treatment 26.47 percent of 7-8 years old males and 42.55 percent of 11 and 14 years old males prefer $(5,7)$ to $(5,5)$, while the corresponding percentage for females are 15 and 27.66 percent.

${ }^{13}$ Our conclusions are confirmed by a set of Probit regressions that are reported in Table A in the on-line Appendix 4.
} 
Result 2: Girls are more averse than boys to both advantageous and disadvantageous inequality but the gender gap in social preferences decreases with age.

\subsection{Lying behavior and social preferences}

In this section we analyze the lying behavior of children, first with respect to age and gender and, next, conditional on their other-regarding preferences. We restrict the analysis to the children who did not observe the shape corresponding to their preferred allocation option and thus had an incentive to lie by misreporting the observed shape. Among these 319 children (50 percent of the total sample), only 14.42 percent $(\mathrm{N}=46)$ lied to obtain their favored outcome. ${ }^{14}$ The fact that a large proportion of the participants reported the truth, independently on any preferences over outcomes, is consistent with the notion that most children are averse to lying. Interestingly, this percentage is close to those reported in a meta-analysis of psychological studies, indicating prevalence rates of 14.4 percent for teachers' reports and 19.4 percent for parents' reports (Stouthamer-Loeber 1986).

Deception and age.- Table 1 displays the distribution of lies by age group, with respect to the type of lie and with respect to multi - clicking on the random device. 12.75 percent of children at age 7-8 lied to get their preferred option; this is roughly 6 percentage points lower than the corresponding fraction of 9-10 year olds (19.20 percent) but this difference

\footnotetext{
${ }^{14}$ This percentage is significantly higher than the percentage of children who misreported the observed shape among those who did observe the shape corresponding to their preferred option (3.46 percent, $\mathrm{N}=11$ ) $(p<0.001$, normal approximation two sample test of equality of independent proportions, two-tailed, $\mathrm{N}=637$, and this is true for each age category. While we acknowledge the possibility that children make errors when taking their decisions, the difference in these percentages suggests that children are more likely to misreport intentionally the observed shape when they do not get their preferred allocation option. One may also hypothesize that some children choose a fair allocation in the first part in order to appear fair in the eyes of the experimenter; in the second part, after observing the shape corresponding to the fair allocation option, they may decide to lie to get the selfish outcome, revealing their true preferences. This hypothesis is not confirmed by our data: 7 of the 11 children who observed their favorite outcome and did not report the true outcome are children who chose a self-regarding allocation in the first part but lied in order to implement the efficiency oriented or the more altruistic option in the second part (i.e. the 5-7 option in the Efficiency treatment).
} 
is not significant $\left(\chi^{2}\right.$-test). In contrast, 9.78 percent of the 11 and 14 year olds lied. Although we cannot reject the null hypothesis that the three bars are not different from each other $(p=0.126$, Kruskal Wallis test, $\mathrm{N}=319)$, our data show that the 9-10 year olds are significantly more prone to lie than older children $\left(p=0.056, \chi^{2}\right.$-test, $\left.N=217\right)$. Since the difference between age groups is not huge, replication is obviously needed to test the robustness of this finding, but this result is in line with the hypothesis developed in psychology by Talwar and Crossman (2011, p.168): “[...] it may be that the developmental trajectory of lying as a normative behavior follows an inverted "U-shaped" function. That is, children's lie-telling might increase to a peak in elementary school, as their cognitive abilities develop and then decrease thereafter due to socialization processes of parents, peers, and others $[\ldots]$ ".

Next, we analyze whether lying behavior differs with respect to age categories because of children lying for different reasons at different ages or whether their attitude towards lying evolves.

\section{[Insert Table 1 about here]}

White and black lies in children.- To study whether having a self- or an other-regarding preference affects children's willingness to lie we consider two types of lies with respect to their consequences. White lies are defined as lies that benefit the other person and black lies as lies that harm the other part, but their characterization differs across treatments. In the Selfishness treatment, a black lie -untruthfully reporting the $(7,3)$ preferred allocation option instead of the observed $(5,5)$ option- provides a monetary benefit to the liar while reducing his partner's payoff. In contrast, a white lie -untruthfully reporting the $(5,5)$ preferred option when observing the $(7,3)$ one- equalizes outcomes by diminishing the liar's payoff and increasing the recipient's payoff. In the Efficiency treatment, a black lie - 
untruthfully reporting $(5,5)$ instead of $(5,7)$ - decreases the other's payoff while providing no monetary benefit to the liar. A white lie -untruthfully reporting $(5,7)$ - increases the recipient's payoff at no monetary cost for the liar. In the Altruism treatment, a black lie untruthfully reporting $(5,5)$ instead of $(3,7)$ - increases the liar's payoff at the expense of his partner, while a white lie -untruthfully reporting $(3,7)$ - benefits the partner to the liar's detriment.

Selfish and envious children are more likely to lie than other-regarding children. Indeed, in the Selfishness treatment, 20 percent of those who prefer $(7,3)$ but observed the $(5,5)$ option told a black lie, while only 4.84 percent of those who prefer $(5,5)$ to the $(7,3)$ option told a white lie ( $p=0.014$, Fisher's exact test, two-sided, N=127). In the Efficiency treatment, 18.63 percent of the envious children who did not observe their favorite option told a black lie while only 5.13 percent of those who prefer $(5,7)$ lied to benefit their partner although such a white lie is free of monetary cost $(p=0.062$, Fisher's exact test, two-sided, $\mathrm{N}=141$ ). In the Altruism treatment, no altruistic child lies whereas 18.75 percent of those who prefer the $(5,5)$ to the $(3,7)$ option tell a black lie.

Although children's concern for others' payoffs develops with age, we find no statistical evidence of an evolution in white $v s$. black lie telling behavior with respect to age. Indeed, Table 1 indicates that across all age categories envy and selfishness are more likely to generate lies than other-regarding preferences. Among the youngest children who did not obtain their preferred option, 15.49 percent told black lies vs. 6.45 percent who told white lies. The corresponding percentages for the 9-10 year olds are 23.33 and 8.57 percent. These percentages are significantly different neither from the oldest children (white lies, $p=0.105$, Fisher's exact test, two-sided, $\mathrm{N}=73$; black lies, $p=0.340, \chi^{2}$-test, $\mathrm{N}=144$ ) nor from the youngest ones $\left(p=0.100\right.$, Fisher's exact test, $\mathrm{N}=66 ; p=0.261, \chi^{2}$-test, $\mathrm{N}=161$, 
respectively for white and black lies). At ages 11 and 14, 16.67 percent told a black lie and no one a white lie.

Finally, we find no significant difference between males and females lying behavior across all age levels. However, the direction of the effect is as predicted by Dreber and Johanesson (2008) for adults: $16.77 \%$ of boys and $12.10 \%$ of girls lied to get their preferred outcome $\left(p=0.246 ; \chi^{2}\right.$-test, two-sided, $\left.\mathrm{N}=319\right)$. When conditioning lying behavior on children's other-regarding preferences, we observe that males are significantly more likely than females to tell black lies ( $p=0.097$, which is consistent with the results by Dreber and Johanesson (2008). 23.58 percent of males but only 14.68 percent of females lied when preferring an equal sharing in the Efficiency and Altruism treatments or the $(7,3)$ option in the Selfishness treatment $\left(p=0.097, \chi^{2}\right.$-test, $\left.\mathrm{N}=215\right)$. Figure 4 displays the frequency of black lies by gender with respect to age. Albeit not significant according to a Fisher's exact test, boys at age 7-8 seem to be more likely than girls to tell black lies (22.86 percent vs. 8.33 percent); this difference disappears in the oldest children. In contrast, females tell more white lies than males but not significantly so (3.57 percent of males and 6.25 percent of females tell white lies; $p=0.660$; Fisher's exact test, two-tailed, $\mathrm{N}=104$ ).

\section{[Insert Figure 4 about here]}

Deception and self-justification.- We expect older children, who possess higher deliberate cognitive resources to reason about their actions, to be more likely to need and search justifications for self-serving unethical behavior. To test this hypothesis, we analyze whether observing the shape corresponding to their preferred allocation option after clicking more than once modifies children's ethical perceptions and their subsequent lying behavior. 
First, we test whether multiple clicking simply reflects a learning/aging effect since this opportunity was not made common information. In fact, the oldest children are not significantly more likely to click more than once than the youngest group, except when they have an incentive to cheat. We find no difference across age categories when considering the entire sample $(10.22,11.20,14.43$ percent respectively for the $7-8,9-10$ and 11-14 years old children, $p>0.10$ ): All children have thus the same ability to click several times.

However, among the children who have not observed the shape corresponding to their preferred option at first, the likelihood of clicking again increases from 7-8 year old (10.78 percent) to 11 and 14 year old children (18.48 percent). Testing the hypothesis that older children are more prone than others to click several times on purpose, we find a significant difference ( $p=0.064$, two-sample proportion test, one-tailed). The fact that the propensity to click several times is correlated with not observing the figure corresponding to one's favorite allocation suggests that multiple clicking is used as a lying strategy.

Next, we investigate whether the lying behavior depends on having observed or not the shape corresponding to the child's preferred option after clicking more than once. Table 1 reports the distribution of liars depending on whether they clicked once or several times, by age category ${ }^{15}$. Among those children who lied, 76.92 percent of the 7-8 year olds misreported the observed shape without clicking again, or, in case they clicked more than

${ }^{15}$ Table 1 reports the percentage of children who lie after activating several times the random device until observing their favorite outcome ("lie with self-justification") and the percentage of children who lie without activating several times the device or after several activations but without observing their favorite outcome ("lie without self-justification"). If we consider the children who lie after multi- clicking vs. those who lie directly, percentages are slightly different $(76.92,58.33$ and 11.11 percent of, respectively, the 7-8, 9-10 and 11 and 14 year old children who misreported the observed shape without clicking again) since those who multi-clicked did not necessarily lie: it depends on whether they have observed their preferred shape after multi-clicking or not. 
once, without ever observing their preferred shape. This percentage decreases to 66.67 for the 9-10 year olds and to 22.22 for the 11 and 14 year olds (a Fisher's exact test confirms a significant difference in behavior when comparing the older group with both 7-8 and 9-10 years old children, $p=0.047$ and $p=0.027$, respectively). Thus, the great majority of older children lied only after having observed their preferred shape when clicking more than once, which is not the case for younger children. ${ }^{16}$ This may capture two effects: $i$ ) older children may have more cognitive resources than younger children to elaborate a strategy using multiple clicking to justify their lie, and ii) they may need more self-justification to preserve their image, which would lead them to be more willing to use this strategy. ${ }^{17} \mathrm{We}$ acknowledge that our design does not allow us to disentangle between these two dimensions, however our study sheds light on when individuals become concerned about feeling honest while distorting the truth. ${ }^{18}$

Econometric analysis.- Table 2 reports Probit regressions in which the dependent variable is the decision to misreport the first observed shape when this shape does not correspond to the preferred allocation option. Five models have been estimated on the pooled data from the three treatments. In model (1), the only independent variable is an other-regarding

\footnotetext{
${ }^{16}$ Note that if younger children were not cognitively able to elaborate a conscious deceptive strategy based on multiple clicks, our results would possibly underestimate the youngest children's willingness to lie and the age difference in the probability to lie.

${ }^{17}$ The most relevant study supporting the fact that older children need more self-justification for lying is Bussey (1999). She examined 4-8-11 years old children's anticipatory evaluative reactions to lies when evaluating vignettes with characters telling white/black lies or telling the truth (i.e. "How would (the vignette character) feel about (herself/himself) for having said (state lie/truth)?"). Anticipated regulatory control was more advanced for the 8- and 11-year-olds, who expected both self-approval for truth-telling and selfdisapproval for lying. Studying children's need for moral justification, Bandura et al. (1996) define moral disengagement as a process of moral justification where detrimental conduct is made personally and socially acceptable through cognitive reconstrual. In a meta-analysis, Gini et al. (2014) found a positive correlation between such moral disengagement and aggressive behavior among children and youth, with a larger effect for adolescents than for children. However, aggressive behavior may differ from lying.

${ }^{18}$ This evidence also suggests that older children do not lie less because they would be more suspicious in their relationship with the IT technology: if more worried than younger children about being monitored via the technology, they should have lied less even after observing their preferred shape when clicking multiple times.
} 
choice in the first stage. This dummy variable takes value 1 if the child expressed otherregarding preferences and 0 otherwise (i.e. $(7,3)$ in the Selfishness treatment or $(5,5)$ in the other treatments). In model (2), the independent variables also include the age categories, with the older children as the reference category. Model (3) augments model (2) by including both a female dummy variable and an interaction term between gender and otherregarding preferences to capture a possible specific influence of social preferences on females compared to males. Model (4) adds a self-justification variable to model (3). This dummy variable takes value 1 if the child observed his preferred shape only after clicking several times. It is equal to 0 if the child either clicked once or clicked several times but without observing his preferred shape. Finally, model (5) augments model (4) by including interaction terms between the self-justification variable and age categories. Table 2 reports marginal effects.

\section{[Insert Table 2 about here]}

All models confirm that holding other-regarding preferences reduces the children's willingness to misreport the truth. In contrast, children prefer to equalize payoffs by lying to avoid the other's payoff exceeding their own $(5,7$ or 3,7$)$ and they are prone to renounce to equal sharing if lying maximizes their own outcome (7,3). Model (2) confirms that children aged 9-10 are more likely to lie than older children. Model (3) indicates that the impact of gender on the probability to lie depends on whether the child has self- or otherregarding preferences: selfish girls are less likely to misreport the truth than boys. In contrast, combining this coefficient with that of the interaction term female*other-regarding preferences reveals that other-regarding girls are more prone to tell lies than boys. Finally, model (4) shows the strong influence of multi-clicking to make one's favorite shape appear on lying behavior. 
We sum up our main findings as follows:

Result 3: Children exhibit a strong lying aversion.

Result 4: In our sample, deception seems to follow a hump-shaped profile across age categories. In addition to a lower proneness to lie - even when a lie could increase the recipient's payoff at no personal cost - older children are more likely to use strategies that may give them a self-justification to lie, compared to younger children.

Result 5: Selfish and envious children are more likely to lie than other-regarding children. Black lies from selfish children are more frequent than white lies from other-regarding children.

Result 6: The gender gap in black lies already exists in childhood: compared to boys, girls are less prone to tell selfish back lies and more prone to tell non-selfish lies.

\section{CONCLUSION}

Important developmental changes occur in children between the ages of 7 and 14. On entering school, social comparisons and interactions with peers become prominent dimensions of a child's development: through aging, children progressively internalize other-regarding preferences. In early adolescence, children become more concerned about efficiency and are more likely to be generous with others. Children progressively base their choices not only on personal gain but also on how their actions will benefit or hurt others. Together with the development of other-regarding preferences, children develop the cognitive ability to lie but also moral reasoning. Although children are taught that lies are morally inappropriate, they may learn that deceit, in some contexts, can be considered as morally acceptable, if lying avoids others being harmed.

We have designed an experiment that allows us to observe both the social preferences of children and their lying behavior. We find that the majority of liars are children who initially expressed selfish preferences and who violated moral rules to satisfy their desire for personal gain or for reasons of envy. 
The evidence presented in this paper suggests that lying behavior does not increase linearly with age and rather seems to follow a hump-shaped time path from middle childhood to early adolescence. This evolution is consistent with the hypothesis that two main forces are driving it. First, older children develop stronger social preferences than those in middle childhood and stronger social preferences are associated with a lower likelihood of lying, even when a lie could benefit the partner at no personal cost. Second, older children are more able and/or more willing than younger ones to develop strategies that allow them to build a self-serving justification when pursuing their self-interest by lying. When aging, the development of internal evaluative reactions leads children to expect self-disapproval when disregarding their internalized moral standards (Bussey 1999). This concern for self-image in dishonesty has been observed in adults (Mazar et al. 2008, Shalvi et al. 2011, Ariely 2012, Fischbacher and Föllmi-Heusi 2013). With our preliminary results, we suggest that this search for self-justification may emerge in late childhood. However, while the pattern of the evolution of social preferences in childhood has been replicated several times, more replication work is needed on the evolution of children's ethical behavior.

We also show that black lies by selfish children are more frequent than white lies by other-regarding children. Children who hold other-regarding preferences are less prone to lie than selfish children for the following possible reasons. A first reason is that children learn at the same time the importance of both ethical and social norms. This may explain why efficiency concerned children are less prone to lie than others although their own payoff is kept constant regardless of their reported option. A second related reason is that other-regarding preferences have been shown to develop later in childhood, thus their role in affecting children's behavior may be weaker with respect to self-regarding preferences. 
Third, the cost of lying is higher for those children holding social preferences. In particular, when they face the less generous option instead of their preferred option, lying requires more effort for other-regarding children than for selfish children. Indeed, it implies not only betraying the moral norm of honesty but also resisting for the second time the temptation of an increased personal payoff. Selfish children who observe the generous option have only to break the ethical norm.

Finally, choosing a fair sharing in the first stage may be part of an image-building strategy. It may then be easier to manage self-image if, after having chosen a fair sharing, the random device gives the child a higher payoff, rather than for a child who behaved selfishly in the first stage. ${ }^{19}$ The current design does not allow us to discriminate between these different explanations. This would probably require eliciting directly the children's norms against white and black lies instead of considering that the perception of norms is reflected in actual behavior. Since asking children to report their beliefs on what others think and what others would do in the same situation would have made our experiment too complicated, we leave this to further investigation.

Overall, we observed a lower propensity to lie in children at all ages compared to most studies on adults. While this evidence is consistent with the hypothesis of pure lying aversion, it may simply suggest that most children view rules as moral absolutes. Although we guaranteed complete privacy in decision-making, we acknowledge, however, that conducting the experiment in schools where respect for rules is important could lead to underestimation of children's propensities to lie, since the environment may influence the decision to behave honestly or not, as shown by Abeler et al. (2014). To reconcile the

\footnotetext{
${ }^{19}$ We thank an anonymous reviewer for suggesting this explanation.
} 
decreasing propensity of lying in children when aging with the higher prevalence of lies in adults, it is suggested that adolescents and young adults learn to develop strategies that allow them to cheat while maintaining their self-image, like using self-deception or moral hypocrisy. The development of self-deception with age in relationship with social preferences would be an interesting extension of this paper. 


\section{REFERENCES}

Abeler, Johannes, Anke Becker, and Armin Falk. 2014. "Representative evidence on lying costs." Journal of Public Economics, 113: 96-104.

Almås, Ingvild, Alexander W. Cappelen, Erik Ø. Sørensen, and Bertil Tungodden. 2010. "Fairness and the Development of Inequality Acceptance." Science, 328(5982): 11761178.

Andersen, Steffen, Seda Ertac, Uri Gneezy, John A. List, and Sandra Maximiano. 2013. Gender, competitiveness and socialization at a young age: evidence from a matrilineal and patriarchal society. The Review of Economics and Statistics, 95(4): 1438-1443.

Ariely, Dan. 2012. The honest truth about dishonesty. Harper Collins.

Bandura, Albert, Claudio Barbaranaelli, Gian Vittorio Caprara, and Concetta Pastorelli. 1996. "Mechanisms of moral disengagement in the exercise of moral agency." Journal of Personality and Social Psychology, 71: 364-374.

Bauer Michal, Julie Chytilová and Barbara Pertold-Gebicka, 2014. "Parental background and other-regarding preferences in children." Experimental Economics, 17(1): 24-46.

Benenson, Joyce F., Joanna Pascoe, and Nicola Radmore. 2007. "Children's Altruistic Behavior in the Dictator Game." Evolution and Human Behavior, 28(3): 168-175.

Blake Peter R., and David G. Rand. 2010. "Currency value moderates equity preference among young children." Evolution and Human Behavior, 31: 210-218.

Broomfield, K.A., Elizabeth J. Robinson, and W. Peter Robinson. 2002. "Children's understanding about white lies." British Journal of Developmental Psychology, 20(1): 47-65.

Bucciol, Alessandro, and Marco Piovesan. 2011. "Luck or cheating? A field experiment on honesty with children." Journal of Economic Psychology, 32(1): 73-78.

Bucciol, Alessandro, Daniel Houser, and Marco Piovesan. 2010. "Willpower in Children and Adults: A Survey of Recent Results and Economic Implications." International Review of Economics, 57(3): 259-267.

Bussey, Kay. 1992. "Lying and truthfulness: Children's definitions, standards, and evaluative reactions." Child Development, 63(1):129-137.

Bussey, Kay. 1999. "Children's categorization and evaluation of different types of lies and truths." Child Development, 70(6): 1338-1347.

Chandler, Michael, Anna S. Fritz, and Suzanne Hala. 1989. "Small-scale deceit: Deception as a marker of two-, three-, and four-year-olds' early theories of mind." Child Development, 60(6): 1263-1277.

Charness, Gary, and Martin Dufwenberg. 2006. "Promises and Partnership." Econometrica, 74(6): 1579-1601.

Childs, Jason. 2012. "Gender differences in lying." Economics Letters, 114(2): 147-149.

Dawes, Christopher T., James H. Fowler, Tim Johnson, Richard McElreath, and Oleg Smirnov. 2007. "Egalitarian motives in humans." Nature, 446(7137): 794-796. 
Donker, Afke, and Pieter Reitsma. 2007. "Young children's ability to use a computer mouse." Computers \& Education, 48(4): 602-617.

Dreber, Anna, and Magnus Johannesson. 2008. "Gender differences in deception." 99: 197199.

Dreber, Anna, Emma von Essen, and Eva Ranehill. 2011. "Outrunning the gender gapboys and girls compete equally." Experimental Economics 14(4): 567-582.

Erat, Sanjiv, and Uri Gneezy. 2012. "White Lies." Management Science, 58(4): 723-733.

Fehr, Ernst, Helen Bernhard, and Bettina Rockenbach. 2008. "Egalitarianism in young children." Nature, 454(7208): 1079 - 1083.

Fehr, Ernst, and Urs Fischbacher. 2003. "The nature of human altruism." Nature, 425(6960): 785-791.

Fehr, Ernst, Daniela Glätzle-Rützler, and Matthias Sutter. 2013. "The Development of Egalitarianism, Altruism, Spite and Parochialism in Childhood and Adolescence." European Economic Review, 64: 369-383.

Fischbacher, Urs. 2007. "z-Tree: Zurich Toolbox for Ready-made Economic Experiments." Experimental Economics, 10(2): 171-178.

Fischbacher, Urs, and Franziska Föllmi-Heusi. 2013. "Lies in disguise - An experimental study on cheating." Journal of the European Economic Association, 11(3): 1542-4774.

Gervais, Jean, Richard E. Tremblay, Lyse Desmarais-Gervais, L., and Frank Vitaro. 2000. "Children's persistent lying, gender differences, and disruptive behaviors: A longitudinal perspective." International Journal of Behavioral Development, 24(2): 213-221.

Gibson, Rajna, Carmen Tanner, and Alexander F. Wagner. 2013. "Preferences for truthfulness: Heterogeneity among and within individuals." American Economic Review, 103(1): 532-548.

Gini, Gianluca, Pozzoli, Tiziani, and Hymel, Shelley. 2014. "Moral disengagement among children and youth: A meta analytic review of links to aggressive behavior." Aggressive Behavior, 40: 56-68.

Glätzle-Rützler, Daniela and Philipp Lergetporer, 2014. "Lying and Age: An Experimental Study." Journal of Economic Psychology, doi: http://dx.doi.org/10.1016/j.joep.2014.11.002.

Gneezy, Uri. 2005. "Deception: The Role of Consequences." American Economic Review, 95(1): 384-394.

Gneezy, Uri, and Aldo Rustichini. 2004. "Gender and Competition at a Young Age." American Economic Review 94(2): 377-381.

Harbaugh, William T. and Kate Krause. 2000. "Children's altruism in public good and dictator experiments." Economic Inquiry 38(1): 95-109.

Harbaugh, William T., Kate Krause, and Lise Vesterlund. 2002. "Risk Attitudes of Children and Adults: Choices Over Small and Large Probability Gains and Losses." Experimental Economics 5(1): 53-84.

Harbaugh, William, Kate Krause, Steve Liday, and Lise Verserlund. 2003. "Trust in 
children." In Trust, Reciprocity and Gains from Association: Interdisciplinary Lessons from Experimental Research, by Elinore Ostrom and James Walker. New York City: Russell Sage Foundation.

Harbaugh, William, Kate Krause and Steve Liday. 2003. "Bargaining by children". University of Oregon Economics Department Working Paper No. 2002-04.

Henrich, Joseph. 2001. "In Search of Homo Economicus: Behavioral Experiments in 15 Small-Scale Societies." American Economic Review, 91(2): 73-78.

Hurkens, Sjaak, and Navin Kartik. 2009. "Would I lie to you? On social preferences and lying aversion." Experimental Economics, 12(2): 180-192.

Irlenbusch, Bernd, and Marie Claire Villeval. 2015. "Behavioral ethics: how psychology influenced economics and how economics might inform psychology?" Current Opinion in Psychology, 1(6):87-92.

Lewis, Michael, Catherine Stanger, and Margaret W. Sullivan. 1989. "Deception in 3-YearOlds." Developmental Psychology, 25(3): 439-443.

López-Pérez, Raúl, and Eli Spiegelman. 2013. "Why do people tell the truth? Experimental evidence for pure lie aversion." Experimental Economics, 16(3): 233-247.

Lundquist, Tobias, Tore Ellingsen, Erik Gribbe, and Magnus Johannesson. 2009. "The Aversion to Lying." Journal of Economic Behavior \& Organization, 70(1-2): 81-92.

Martinsson, Peter, Katarina Nordblom, Daniela Rützler, and Matthias Sutter. 2011. "Social preferences during childhood and the role of gender and age. An experiment in Austria and Sweden." Economics Letters, 110(3): 248-251.

Mazar, Nina, On Amir, and Dan Ariely. 2008. "The Dishonesty of Honest People: A Theory of Self-Concept Maintenance." Journal of Marketing Research, 46(6): 633-644.

Piaget, Jean. 1965. The moral judgment of the child. New York: The Free Press.

Pittarello Andrea, Margarita Leib, Tom Gordon-Hecker, and Shaul Shalvi. 2015. "See what you want to see: justifications shape ethical blind spots." Forthcoming in Psychological Science. doi: 10.1177/0956797615571018

Pruckner, Gerald J., and Rupert Sausgruber. 2013. "Honesty on the Streets: A Field Study on Newspaper Purchasing. " Journal of the European Economic Association, 11(3): 661679.

Shalvi Shaul, Jason Dana, Michel J.J. Handgraaf, and Carsten K.W. De Dreu. 2011. "Justified ethicality: Observing desired counterfactuals modifies ethical perceptions and behavior." Organizational Behavior and Human Decision Processes, 115:180-191.

Shepherd, M., B. Oppenheim, and S. Mitchell. 1971. Childhood behavior and mental health. London: University of London Press.

Stouthamer-Loeber, Magda. 1986. "Lying as a problem behavior in children: a review." Clinical Psychology Review, 6: 267-289.

Sutter, Matthias, and Martin G. Kocher. 2007. "Trust and trustworthiness across different age groups." Games and Economic Behavior, 59(2): 364-382.

Sutter, Matthias, and Daniela Rützler. 2010. "Gender differences in competition emerge 
early in life." Journal of Labor Economics, 8(1): 123-144.

Sutter, Matthias, Martin G. Kocher, Daniela Glätzle-Rüetzler, and Stefan T. Trautmann. 2013. "Impatience and Uncertainty: Experimental Decisions Predict Adolescents' Field Behavior." American Economic Review, 103(1): 510-531.

Talwar, Victoria, and Angela Crossman. 2011. "From little white lies to filthy liars: The evolution of honesty and deception in young children." Advances in Child Development and Behavior, 40: 139-179.

Talwar, Victoria, and Kang Lee. 2008. "Social and Cognitive Correlates of Children's Lying Behavior." Child Development, 79(4): 866-81.

Talwar, Victoria, Heidi M. Gordon, and Kang Lee. 2007. "Lying in the elementary school: Verbal deception and its relation to second-order belief understanding." Developmental Psychology, 43(3): 804-810.

Tricomi, Elizabeth, Antonio Rangel, Colin F. Camerer, and John P. O'Doherty. 2010. "Neural evidence for inequality-averse social preferences." Nature, 463(7284): 10891091.

Vanberg, Cristoph. 2015. "Who never tells a lie?" University of Heidelberg Economics Department Working Paper No. 581.

$\mathrm{Xu}$, Fen, Xuehua Bao, Genyue Fu, Victoria Talwar, and Kung Lee. 2010. "Lying and truthtelling in children: from concept to action." Child Development, 81(2): 581-596. 


\section{FIGURES AND TABLES}

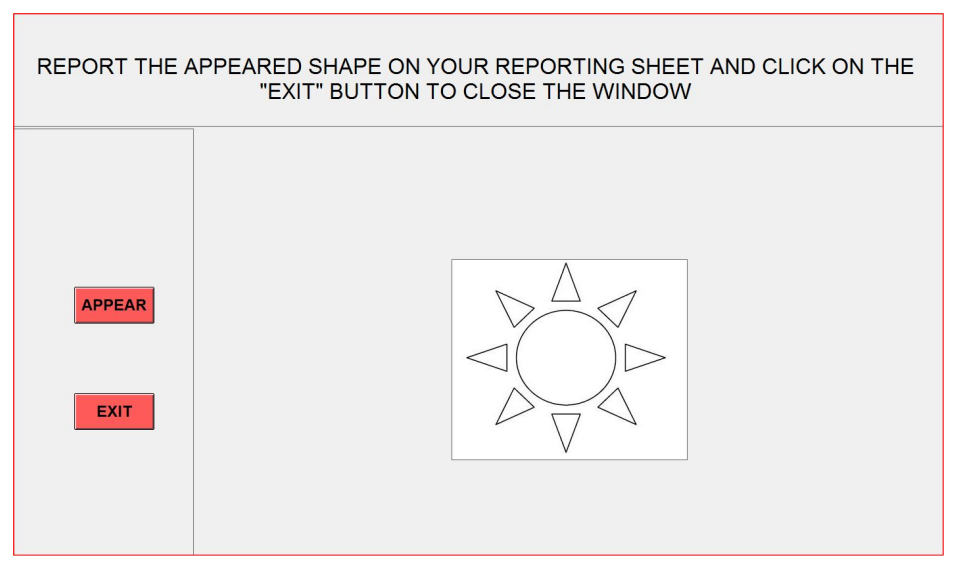

\begin{tabular}{||l|}
\hline Player number___ Class _ \\
$\mathbf{5}$ tokens for me \\
$\mathbf{5}$ tokens fot the other kid
\end{tabular}

FIGURE 1. SCREENSHOT AND REPORTING SHEET IN STAGE 2

Note: The figure on top displays an example of the screenshot used in the second stage of the experiment. The figure at the bottom represents the reporting sheet that children had to fill out after making a shape appear on their computer screen. 


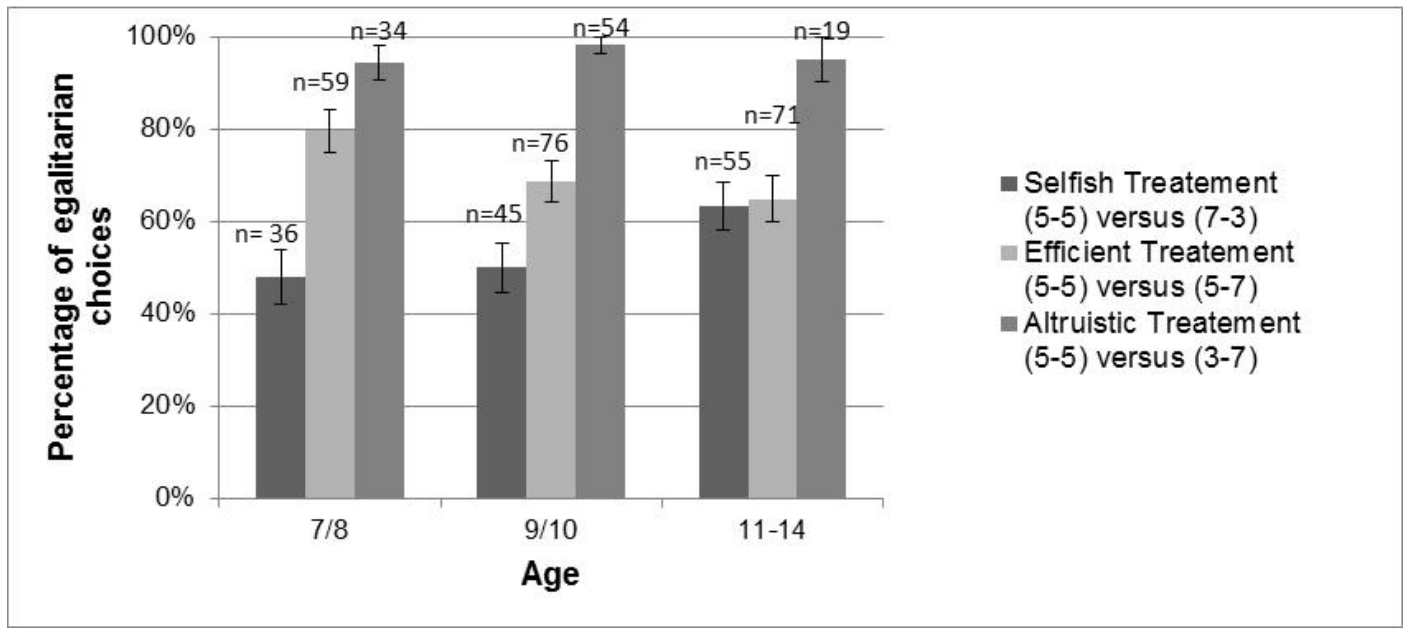

FIGURE 2. FREQUENCY OF EGALITARIAN CHOICES ACROSS AGE GROUPS

Notes: In the Selfishness treatment, the frequency of egalitarian choices increases with age. In the Efficiency treatment, where the alternative option allows children to augment other's payoff at no cost, the 11-14 year olds are more prone to renounce to share points equally. In the Altruism treatment, most children choose the egalitarian allocation independently of age groups. Error bars illustrate standard errors (SEM). 


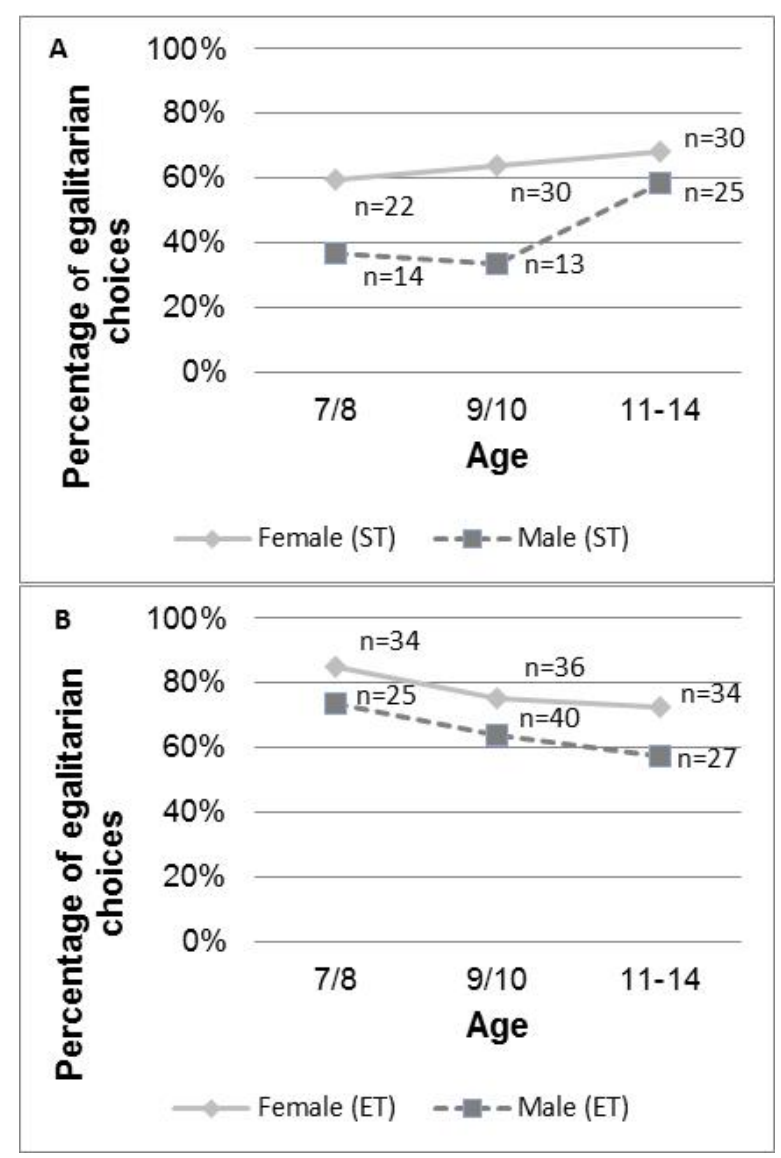

FIGURE 3. GENDER DIFFERENCES IN EGALITARIAN CHOICES

Notes: The solid lines represent the percentages of egalitarian choices of females; the dashed lines represent the corresponding percentages for males. In the Selfishness treatment (A) the choice is between $(5,5)$ and $(7,3)$ whereas in the Efficiency treatment $(B)$ the choice is between $(5,5)$ and $(5,7)$. (A) shows that boys become less selfish as they age; girls are more likely to share equally at all ages but the gap reduces at older ages. (B) shows that both males and females develop a concern for efficiency as they age; the gender gap is small but persistent. 


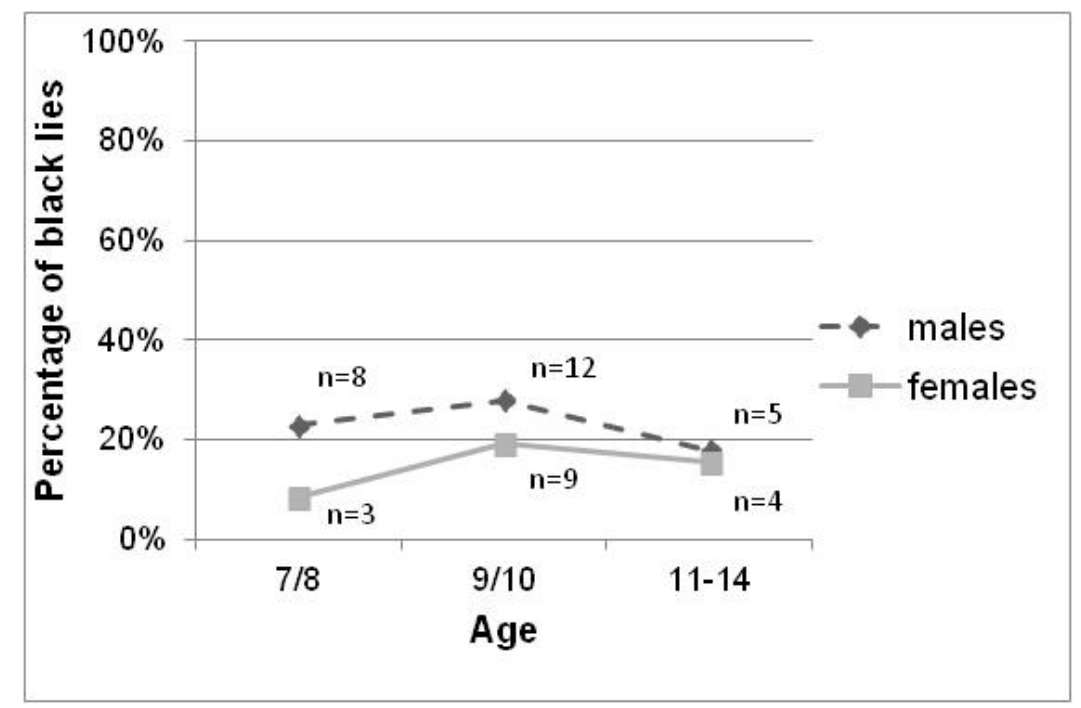

FIGURE 4. LYING GENDER DIFFERENCES IN BLACK LIES

Notes: This figure displays the percentage of children by gender and age group who tell a lie that decreases the other's payoff, among those who did not observe their preferred allocation option in the second part of the experiment. The dashed line is for males; the solid line is for females. Males are more likely to lie than females, but this difference disappears for older children. 
TABLE 1 - SUMMARY STATISTICS - LYING BEHAVIOR

\begin{tabular}{lcccc}
\hline \hline & \multicolumn{3}{c}{ Age } & Total \\
\cline { 2 - 4 } & $7 / 8$ & $9 / 10$ & $11-14$ & \\
\hline Percentage of lies & $12.75(13 / 102)$ & $19.20(24 / 125)$ & $9.78(9 / 92)$ & $14.42(46 / 319)$ \\
- share of black lie & $15.49(11 / 71)$ & $23.33(21 / 90)$ & $16.67(9 / 54)$ & $19.07(41 / 215)$ \\
- share of white lies & $6.45(2 / 31)$ & $8.57(3 / 35)$ & 0 & $4.81(5 / 104)$ \\
\hline $\begin{array}{l}\text { Percentage of } \\
\text { - lies with multi- }\end{array}$ & $23.08(3 / 13)$ & $33.33(8 / 24)$ & $77.78(7 / 9)$ & $39.13(18 / 46)$ \\
$\begin{array}{c}\text { clicking } \\
\text { - lies without multi- } \\
\text { clicking }\end{array}$ & $76.92(10 / 13)$ & $66.67(16 / 24)$ & $22.22(2 / 9)$ & $60.87(28 / 46)$ \\
\hline
\end{tabular}

Notes: A "lie with self-justification" means that the subject has reported his preferred outcome after activating several times the random device until observing his favorite outcome. A "lie without self-justification" means that the subject has reported his preferred outcome without activating several times the random device or after several activations but without observing his/her favorite outcome. 
TABLE 2-CHILDREN'S LYING BEHAVIOR

\begin{tabular}{|c|c|c|c|c|c|}
\hline & $(1)$ & (2) & (3) & (4) & $(5)$ \\
\hline Other-regarding & $-0.143 * * *$ & $-0.137 * * *$ & $-0.179 * * *$ & $0.152 * * *$ & $0.148 * * *$ \\
\hline preferences & $(0.034)$ & $(0.034)$ & $(0.036)$ & $(0.032)$ & $(0.032)$ \\
\hline $7-8$ year olds & - & $\begin{array}{l}0.026 \\
(0.04)\end{array}$ & $\begin{array}{c}0.024 \\
(0.041)\end{array}$ & $\begin{array}{c}0.073 \\
(0.055)\end{array}$ & $\begin{array}{l}0.157 * * \\
(0.077)\end{array}$ \\
\hline $9-10$ year olds & - & $\begin{array}{l}0.082^{*} \\
(0.050)\end{array}$ & $\begin{array}{l}0.084^{*} \\
(0.049)\end{array}$ & $\begin{array}{c}0.122 * * * \\
(0.047)\end{array}$ & $\begin{array}{c}0.159 * * * \\
(0.066)\end{array}$ \\
\hline Female & - & - & $\begin{array}{l}-0.070^{*} \\
(0.040)\end{array}$ & $\begin{array}{l}-0.068^{*} \\
(0.036)\end{array}$ & $\begin{array}{l}-0.063^{*} \\
(0.034)\end{array}$ \\
\hline $\begin{array}{l}\text { Female * Other- } \\
\text { regarding pref. }\end{array}$ & - & - & $\begin{array}{c}0.156 * * \\
(0.080)\end{array}$ & $\begin{array}{l}0.122 * * \\
(0.074)\end{array}$ & $\begin{array}{l}0.113^{*} \\
(0.075)\end{array}$ \\
\hline $\begin{array}{l}\text { Justification with } \\
\text { multi clicking }\end{array}$ & - & - & - & $\begin{array}{l}0.565 * * * \\
(0.111)\end{array}$ & $\begin{array}{c}0.767 * * * \\
(0.179)\end{array}$ \\
\hline $\begin{array}{l}\text { Justification * 7-8 } \\
\text { year olds }\end{array}$ & & & & & $\begin{array}{l}-0.094 \\
(0.020)\end{array}$ \\
\hline $\begin{array}{l}\text { Justification } * 9- \\
10 \text { year olds }\end{array}$ & & & & & $\begin{array}{l}-0.065 \\
(0.055)\end{array}$ \\
\hline Number of observ. & 319 & 319 & 319 & 319 & 319 \\
\hline Log-pseudolikelih. & -124.808 & -123.177 & -121.486 & -99.390 & -97.331 \\
\hline Pseudo $\mathrm{R}^{2}$ & 0.051 & 0.064 & 0.076 & 0.24 & 0.26 \\
\hline Wald test & 9.25 & 3.54 & 5.59 & 32.6 & 2.79 \\
\hline$\left(\chi^{2}, p\right.$-value $)$ & $(<0.01)$ & $(0.17)$ & $(0.061)$ & $(<0.01)$ & $(0.25)$ \\
\hline
\end{tabular}

Notes: This Table presents the marginal effects in Probit regressions. The dependent variable is the decision to lie. Standard errors adjusted for 34 clusters (class) appear in parentheses. ***,** and * indicate significance at the 1 percent level, at the 5 percent level and at the 10 percent level, respectively. 


\section{On-line Appendix 1 - Experimental instructions (translated from Italian)}

\section{Introduction}

Hi everybody! How are you? (children answer) My name is Valeria, this is Daniela and this is Giulia. First of all, thanks a lot for letting us come to your school today. It is really nice to be here. Today we are going to play a simple game! Only children whose parents have signed the consent form will participate in the game. If your parents have not signed the consent form, please stay quiet. You are free to not participate in the game if you do not want to, just raise your hand and wait.

\section{Identification}

First of all, you will randomly pick a tag with a random number on it, because it is too difficult for us to remember all your names! Please, attach your number to your shirt. You are not allowed to change your number with others. Please keep this number with you until the end of the game.

Each child picks a number from a bag.

Are you ready? If you do not understand something of this explanation, do not worry: before playing the game I will individually explain to each participant the rules of the game one more time. I will then privately answer all your questions.

\section{Explanations of the rules to the class}

Let's start by explaining the rules of the game. Please pay attention and be quiet! In this game you will have the possibility to earn some tokens that you can exchange at the end of the experiment for pencils, shokkhy-bandz, etc.

An assistant shows the 'prizes' to children (see Figure S5).

As you can see, there are enough pencils, shokky-bandz, etc. for everybody. Obviously, the more tokens you have, the more things you can get.

This game consists of two parts and you will get the tokens you have earned in just one of these two parts: this part will be randomly selected at the very end of the game. Which part to consider in order to give you the tokens DOES NOT DEPEND on the choices you will take, it is completely random.

Now, I am going to explain you the first part of the game: please pay attention and be quiet. If you have any questions I will answer them privately and individually before playing the game.

This game is played in pairs. You are going to be randomly paired with one of your classmates. You will never know which child is your partner in this game.

Remember that you cannot choose your partner, s/he will be chosen at random.

You will play this game one by one, using a computer. Do not worry, this game is really simple, and if you have any doubts, I will answer all your questions before you play it!

In the first part of the game, you have to make a decision: you have to decide how to divide 10 tokens between yourself and your partner. You will take this decision alone, and your parents, your classmates, your teachers will never know what was your choice, not even at the end of the game. One by one, you will leave the classroom, go to another room and make your decision by clicking on the computer screen. 
This is what you will see on the computer:

An assistant shows the following poster showing the screenshot for the first part of the game As you can see, there are two possible ways to allocate the tokens between you and the other kid: the option on the left-hand side and the option on the right-hand side. The option on the left-hand side will

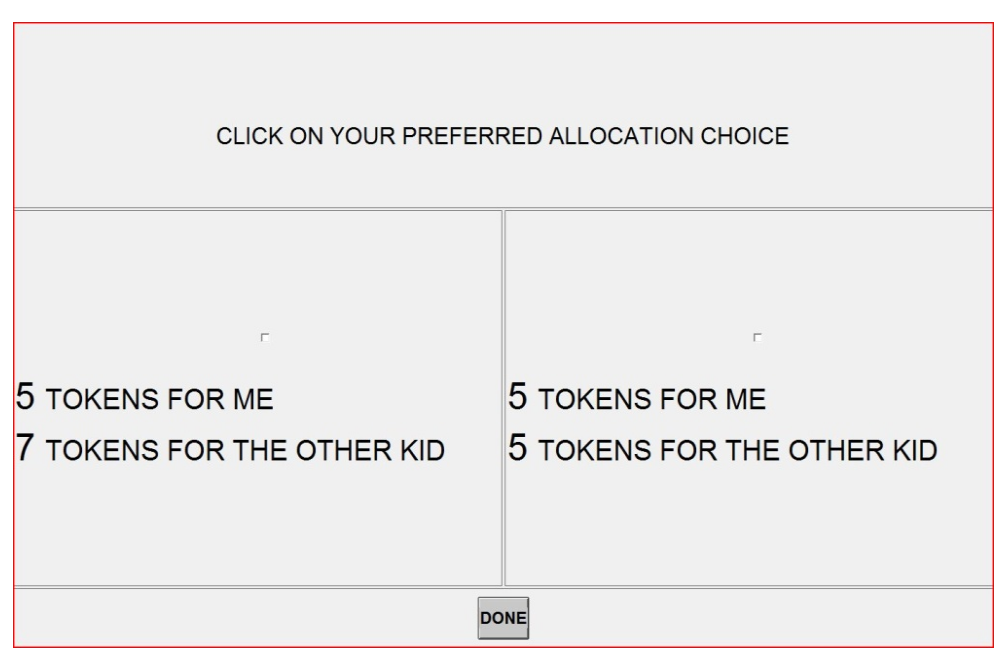
give to you and to the other kid the same amount of tokens, that is 5 , whereas the right-hand side option will give $5 / 7 / 3$ tokens to you and $7 / 3$ tokens to the other kid. You have to tick the option you prefer by clicking on it. After you have ticked your preferred option, you have to click on the "done" button and wait. Remember that there are no correct or incorrect choices, just choose the option that you prefer.

You will take this decision alone. The other children, the teacher, your friends and your parents will never know what was your choice. Remember that your choice is private, so you are not allowed to speak about it until the very end of the game.

The explanation of the first part of the game is finished... as you have seen, it is a very simple game! If you have not understood what you have to do, do not worry, before playing the game I am going to individually explain to you the rules of the first part of the game and I will answer all your questions.

Let's start with the second part of the game! Are you ready? Please remember that you are going to get only the tokens you have earned in only one of the two parts of the game: this part will be randomly selected!

After you have clicked on your preferred allocation choice and on the "done" button in the first part of the game, the second part of the game begins. In the second part of the game you will firstly see this screen.

An assistant shows the following poster showing the screenshot for the second part of the game

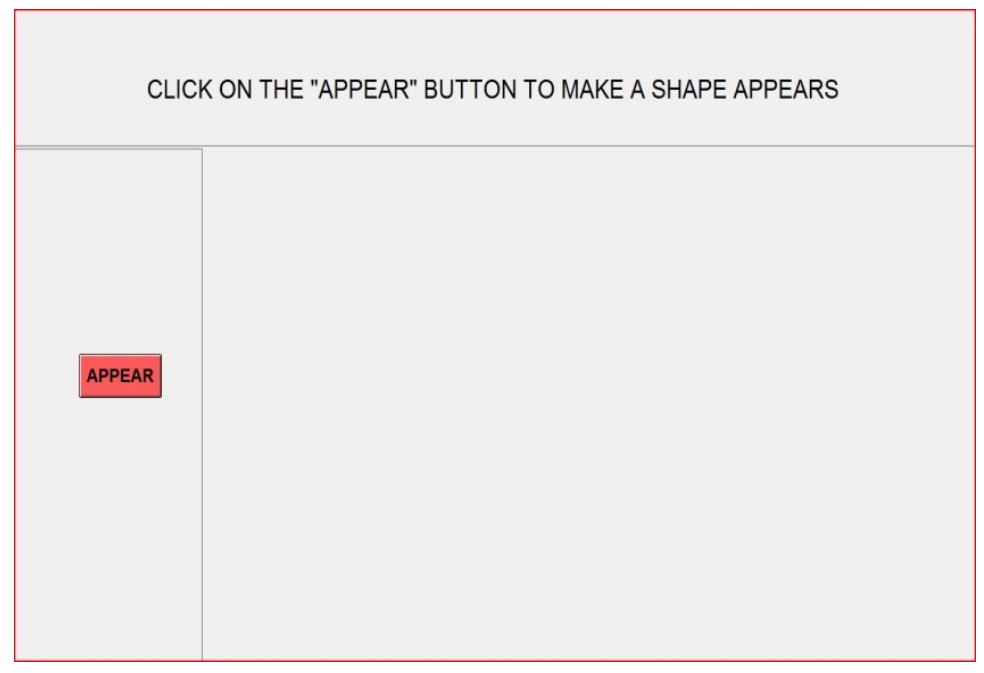

As you can see, this screen asks you to click on the "APPEAR" button in order to make a picture appear. Which picture? A sun or a star! As you click on this "APPEAR" button you will see a sun or a star. In the computer there are as many suns as stars, so you will see one of the two at random. Some of you will see a star, some others will see a sun.

An assistant shows the sun and the star to the children. 

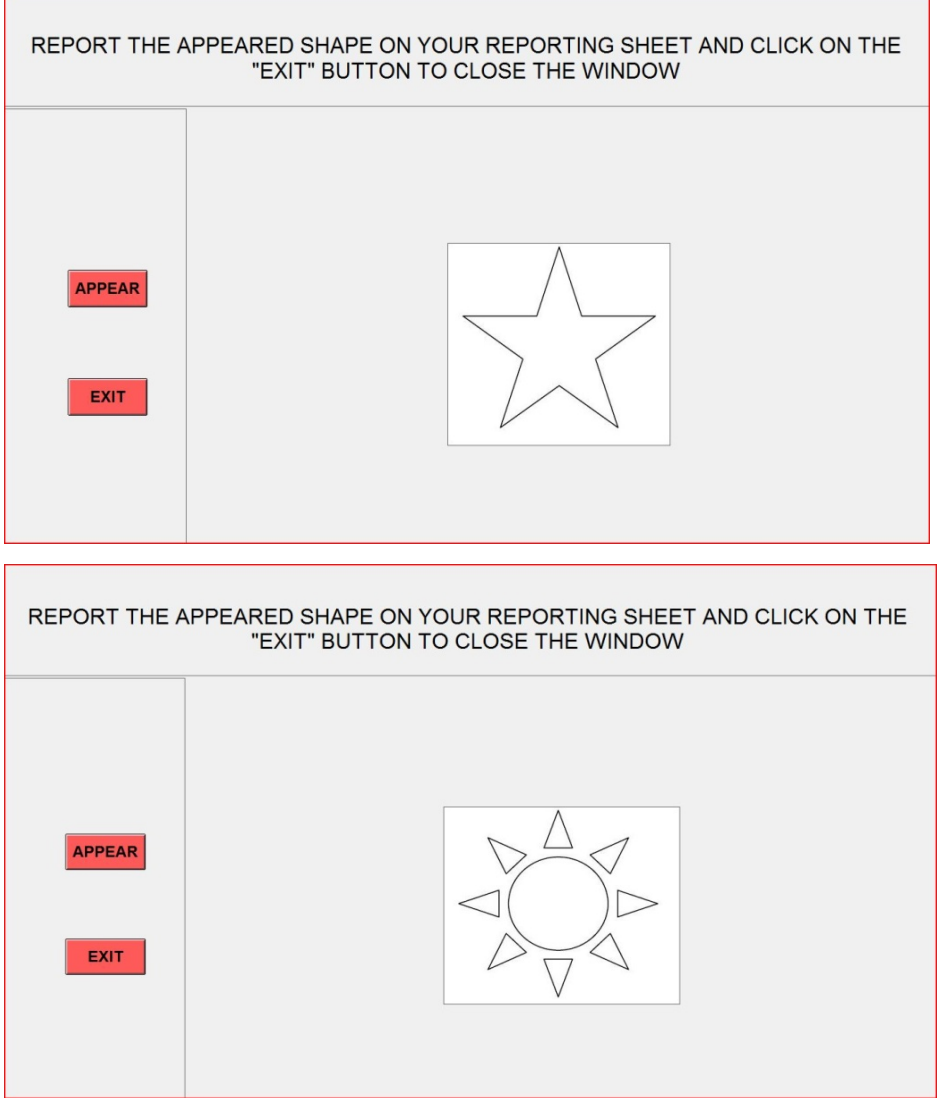

Once you have seen the shape, you have to report which picture you have seen in this reporting sheet.

An assistant shows the reporting sheet to the children.

\begin{tabular}{|l|l|}
\hline Player number___ Class_- \\
$\begin{array}{l}\mathbf{5} \text { tokens for me } \\
\mathbf{5} \text { tokens fot the other kid }\end{array}$ \\
\hline $\mathbf{5}$ tokens for me
\end{tabular}

As you can see, this reporting sheet is similar to the computer screen I have just shown you in the first part of the game. The only difference is that you have two pictures: a sun and a star, one for each of the two options.

If you tick that you have seen the star then both you and the other kid will receive 5 tokens, whereas if you tick you have seen the sun then you will receive 5/7/3 tokens and the other kid will receive $7 / 3$ tokens.

After you have ticked one of the two options in the reporting sheet, you have to exit the game by clicking on the "EXIT" button: the "EXIT" button will close the computer screen. Each of you will tick one of the two options alone and the other children, the teacher, your friends and your parents will never know which option you ticked. 
Once you have clicked on the exit button the screen will go grey and the game will be finished!

After that, you have to put the reporting sheet in the cardboard box and then come back to your classroom. As in the first part of the game, you are not allowed to speak about it until the very end of the game.

At the very end of the game, in order to give you the tokens, we will toss this coin in order to select randomly whether we will consider the decisions made in the first part of the game or the reporting sheets you put in the cardboard box in the second part of the game.

As you can see, in these two bags - a white and a black bag - we have all your numbers: numbers in the white bag are paired with numbers in the black bag. Since all of you have participated in the game, at the end of the experiment we will select randomly between one of the two bags and will distribute the tokens according to the choices these children made.

Remember, however, that you will never know the identity of your partner.

If you do not understand what you have to do, don't worry, before playing the game I am going to individually re-explain to you the rules of the first and the second parts of the game and I will answer all your questions.

Let's start with the game! You can come into the room next door, one by one, and play the game with us. Giulia will call out numbers and when you hear your number it's your turn to play. Giulia will take you to me, where you will play the games. When you are finished the games, you can go back to the classroom and carry on drawing. It's really important to us that you do not talk about the game until all the kids have played. We really want you to follow this rule!

\section{Children play the game}

One assistant calls out the next number and fills in name, surname and number of the child on a table. Each odd numbered child is matched with an even numbered child.

\section{Individual explanation of the rules of the game}

Hi! Now I shall explain to you the rules of the game. If you have any questions, please ask me, I shall be happy to answer them all!

In this game you will be paired up with one of the children in your class. You will never know the identity of the other kid, and the other kid will never know your identity, not even at the end of the game. You have to decide how to divide some tokens between yourself and the other kid.

In the first part of the game, you have to choose between two allocation options and you have to click on the one that you prefer. If you tick the left-hand side option, then both you and the other kid will receive 5 tokens; if you tick the right-hand side option then you will receive $7 / 5 / 3$ tokens whereas the other kid will receive 3/7 tokens. Your friends, your teacher, your classmates and your parents will never know what you chose.

Is it clear? Do you have questions?

After you have clicked on your preferred choice you have to click on the "Done" button. The first part of the game is finished.

In the second part of the game, you have to click on the "Appear" button to make a sun or a star appear. After you have seen the picture, you have to report it on this reporting sheet. 
The child is given a reporting sheet, with his/her own number on it.

If you report the sun, then you and the other kid will both receive 5 tokens; if you report the star then you will receive 7/5/3 tokens whereas the other kid will receive 3/7 tokens. After you have reported the appeared shape in the reporting sheet, you have to click on the EXIT button to exit the game and close the video screen. Finally, you have to put your reporting sheet in the cardboard box.

Your friends, your teacher, your classmates and your parents will never know which option you ticked.

Remember that you will receive the tokens according to the decisions you make either in the first or in the second part of the game, and this will be random.

Is it clear? Do you have questions?

\section{Distribution of the 'prizes', after all children have played the game}

After all kids have played the game, one assistant tosses a coin to determine whether children will be paid according to the choices made in the first or in the second part of the game. The coin is tossed again to determine whether children will be paid according to the choices made by the children whose number is contained in the white bag or by the children whose number is contained in the black bag.

Now that all the children have played the game, we will tell each of you how many tokens you have won and we will exchange them for what you want, according to this rule:

The following exchange rule is written on the blackboard.

3 tokens: you can get 1 colored pen/pencil or 1 packet of stickers or 5 shokky-bandz.

5 tokens: you can get 2 colored pens/pencils or 2 packets of stickers or 10 shokky-bandz. You can also mix the prizes and get 1 pen/pencil and 1 packet of stickers or 1 packet of stickers and 5 shokky-bandz, etc.

7 tokens: you can get 3 colored pens/pencils or 3 packets of stickers or 1 packet of shokkybandz. You can also mix the prizes and get 1 colored pen/pencil, 5 shokky-bandz and 1 packet of stickers or 2 packets of stickers and 5 shokky-bandz, etc.

When I call your number please come here: I will tell you how many tokens you have won so that you can choose the prize you want.

Once you get the prize, please put it in your schoolbag and keep quiet.

\section{Individual distribution of the prize}

Hi, you have won 3/5/7 tokens! You can get these items, what do you want? Do you like the prize?

\section{End of the experiment}

Thank you very much for participating in this game! We really enjoy our staying! Now you will continue your lesson with Professor xxx. Please, remember not to talk with the others about the game! Bye bye! 
On-line Appendix 2. The decision-making environment

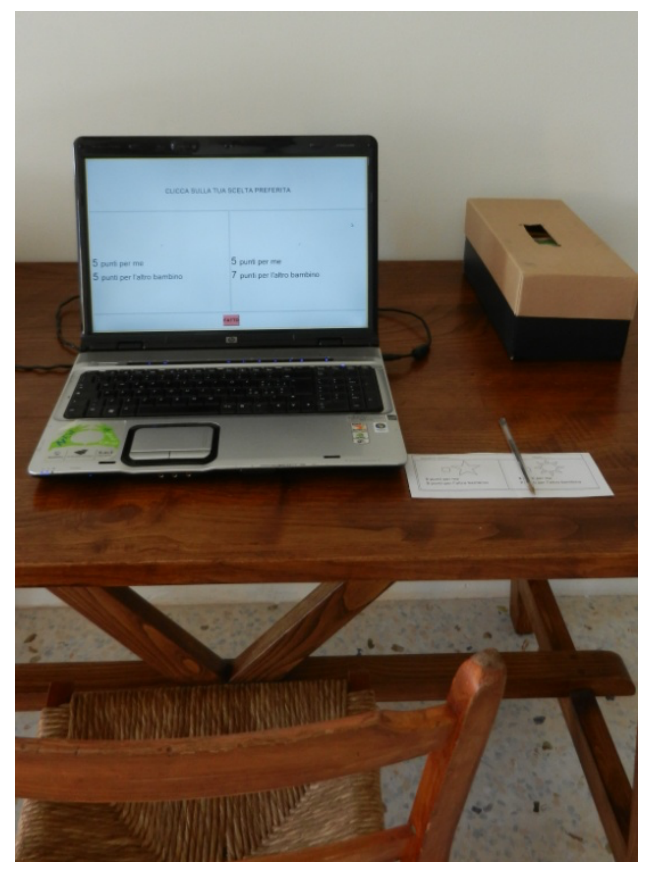

Note: This picture shows the experimental set up in the decision room: a computer, the reporting sheet and the cardboard box. 
On-line Appendix 3. Prizes in the experiment

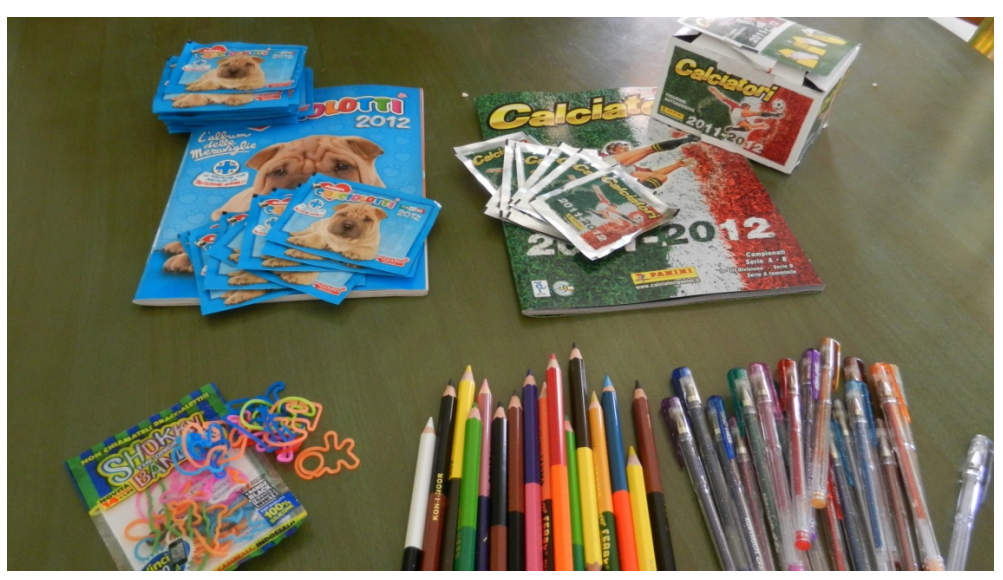

Note: This picture shows the prizes that children could get in exchange for the earned tokens: stickers, colored pens and pencils, "shokky-bandz". 


\section{On-line Appendix 4 - A Probit analysis of the determinants of other-regarding}

\section{preferences}

To complement our non-parametric analysis of the influence of age, gender and treatments on children's choices, we ran Probit regressions in which the dependent variable is the binary choice of the egalitarian option $(5,5)$ in the first stage of the game. We control for the potential role of similar characteristics of child's classmates by clustering errors at the class level. In these regressions we pool data from the Selfishness and the Efficiency treatments. We exclude the data from the Altruism treatment because there is almost no variation in decisions.

In model (1), the only independent variable is the Selfishness treatment. This variable takes value 1 if the child participated in the Selfishness treatment, and 0 if he participated in the Efficiency treatment. In model (2), we add age categories. These variables are dummy variables. We interact each age category with the Selfishness treatment variable. Since the omitted category is the 11 and 14 years old children who participated in the Efficiency treatment, the 7-8 and 9-10 variables measure the age trends in choosing the egalitarian choice in the Efficiency Treatment. Finally, the interaction terms between the Selfishness treatment and each age category measure the differences in the probability of choosing the egalitarian choice between the Selfishness and the Efficiency treatments in each age category versus the difference in the oldest children. In model (3), we include a female dummy variable and an interaction term between the treatment and the gender variables. Finally, model (4) includes all the previous independent variables. Table A displays marginal effects.

\begin{tabular}{lcccc}
\multicolumn{5}{c}{ TABLE A-ROLE OF CHILDREN'S AGE AND GENDER ON OTHER-REGARDING PREFERENCES } \\
\hline & $(1)$ & $(2)$ & $(3)$ & $(4)$ \\
\hline Selfishness treatment (ST) & $-0.167 * * *$ & -0.017 & $-0.205^{* *}$ & -0.052 \\
& $(0.056)$ & $(0.106)$ & $(0.078)$ & $(0.119)$ \\
7-8 year olds & - & 0.162 & - & 0.159 \\
& & $(0.117)$ & & $(0.120)$ \\
9-10 year olds & - & 0.050 & - & 0.058 \\
& - & $(0.097)$ & & $(0.095)$ \\
7-8 year olds * ST & $-0.324^{* *}$ & - & $-0.323^{*}$ \\
& - & $(0.158)$ & & $(0.160)$ \\
9-10 year olds * ST & -0.183 & - & $-0.204^{*}$ \\
& & $(0.125)$ & & $(0.125)$ \\
Female & & - & $0.135^{* *}$ & $0.132^{* *}$ \\
& - & - & $(0.063)$ & $(0.065)$ \\
Female * ST & & & 0.069 & 0.069 \\
& 525 & 525 & $(0.092)$ & $(0.094)$ \\
\hline \# observations & -338.485 & -333.827 & -330.563 & -325.879 \\
Log pseudo-likelihood & 0.023 & 0.036 & 0.046 & 0.059 \\
Pseudo R & & 5.3 & 12.35 & 15.87 \\
Wald test statistic & 15.6 & $(0.26)$ & $(<0.01)$ & $(<0.05)$ \\
$\chi^{2}, p$-value) & $(<0.01)$ & &
\end{tabular}

Note: $* * *, * *$, and $*$ indicate significance at the 1 percent, 5 percent and 10 percent level, respectively.

Model (1) shows that children are less likely to choose the egalitarian option when the alternative option allows them to increase their own payoff instead of the other's one. Model (2) reveals that this effect is mainly due to the youngest children. Indeed, the interaction term 7-8 year olds*Selfishness treatment measures the difference in the probability of choosing the egalitarian 
choice between the Selfishness and the Efficiency treatments in the youngest group versus the difference in the oldest children: a negative coefficient means that the difference between the Selfishness treatment and the Efficiency treatment declines with age, i.e. as children become older, they choose less often the (5-5) option in the Efficiency treatment and more often the (5-5) option in the Selfishness treatment. Model (3) indicates that girls are significantly more prone than boys to share tokens equally, independently on the available alternative option. As shown by the insignificant interaction term between the Selfishness treatment and gender in models (3) and (4), the impact of children's gender on the probability to choose the egalitarian option is the same regardless of the treatment. 